\title{
Risk management in medical product development process using traditional FMEA and fuzzy linguistic approach: a case study
}

\author{
Milind Shrikant Kirkire ${ }^{1}\left[\right.$ - Santosh B. Rane ${ }^{1} \cdot$ Jagdish Rajaram Jadhav $^{2}$
}

Received: 14 August 2014/ Accepted: 11 May 2015/Published online: 27 May 2015

(C) The Author(s) 2015. This article is published with open access at Springerlink.com

\begin{abstract}
Medical product development (MPD) process is highly multidisciplinary in nature, which increases the complexity and the associated risks. Managing the risks during MPD process is very crucial. The objective of this research is to explore risks during MPD in a dental product manufacturing company and propose a model for risk mitigation during MPD process to minimize failure events. A case study approach is employed. The existing MPD process is mapped with five phases of the customized phase gate process. The activities during each phase of development and risks associated with each activity are identified and categorized based on the source of occurrence. The risks are analyzed using traditional Failure mode and effect analysis (FMEA) and fuzzy FMEA. The results of two methods when compared show that fuzzy approach avoids the duplication of RPNs and helps more to convert cognition of experts into information to get values of risk factors. The critical, moderate, low level and negligible risks are identified based on criticality; risk treatments and mitigation model are proposed. During initial phases of MPD, the risks are less severe, but as the process progresses the severity of risks goes on increasing. The MPD process should be critically designed and simulated to
\end{abstract}

Milind Shrikant Kirkire

milind.kirkire@gmail.com

Santosh B. Rane

s_rane@spce.ac.in

Jagdish Rajaram Jadhav

jrjadhav70@gmail.com

1 Department of Mechanical Engineering, Sardar Patel College of Engineering, Andheri, Mumbai, India

2 Department of Mechanical Engineering, K. J. Somaiya Polytechnic, Vidyavihar, Mumbai, India minimize the number of risk events and their severity. To successfully develop the products/devices within the manufacturing companies, the process risk management is very essential. A systematic approach to manage risks during MPD process will lead to the development of medical products with expected quality and reliability. This is the first research of its kind having focus on MPD process risks and its management. The methodology adopted in this paper will help the developers, managers and researchers to have a competitive edge over the other companies by managing the risks during the development process.

Keywords Risk management - MPD process - FMEA Fuzzy theory - RPNs - Case study

\section{Introduction}

Medical devices are special products that are directly related to patient's health and lives (Lin et al. 2014). Bringing a new medical product successfully from the bench to beside is highly complex and depends heavily on the implementation of rigorous processes. These processes need to allow developers to optimally phase development, testing, and other activities, and to successfully execute on the manifold requirements of third parties, including regulators and payers. These additional requirements set medical product/device development apart from the development of other products (Pietzsch et al. 2009).

According to I.S. EN ISO 14971 (2012), medical device means any instrument, apparatus, implement, machine, appliance, in vitro reagent or calibrator, software, implant, reagent, material or other similar or related article, intended by the manufacturer to be used, alone or in 
combination, for human beings for one or more of the specific purposes:

- diagnosis, prevention, monitoring, treatment or alleviation of disease,

- diagnosis, monitoring, treatment, alleviation of or compensation for an injury or disability,

- investigation, replacement, modification or support of the anatomy or of a physiological process or state,

- supporting or sustaining life,

- control or support of conception,

- disinfection or sterilization of any of the abovementioned devices,

- providing information for medical purposes by means of in vitro examination of specimens derived from the human body, and which does not achieve its principal intended action by pharmacological, immunological or metabolic means in or on the human body; but which may be assisted in its function by such means.

\section{Medical device classification}

North American Industry Classification System (NAICS) has classified the medical devices industry that is covered by the Office of Health and Consumer Goods (OHCG) as illustrated in Fig. 1.

USFDA did analysis based on the data available with them and interviews conducted with the thought leaders. It reported that medical device companies lack expertise in developing risk assessment and mitigation plans during the product development phases. This significantly impairs their ability to monitor and control quality through the manufacturing and the post-production phases. Risk assessment tools like design and process failure mode and effects analysis (FMEAs) are often not developed, applied appropriately (Understanding Barriers to Medical Device Quality, FDA report, Oct. 31, 2011).

Failure mode and effect analysis (FMEA) is the commonly used technique in RM of medical products/devices. It has got several drawbacks; this paper uses fuzzy FMEA to compare results with traditional FMEA for RM in MPD process. However, FMEA and ISO 14971 approaches are rarely carried out in an integrated manner, either in theory or in practice. Risk analysis and failure analysis in industry lack guidance as well as showcase (Chan et al. 2012). In particular, FMEA is often implemented to improve device reliability and quality, as well as to correct potential problems (with an intention to satisfy the ISO9000 and QS9000 requirements), while ISO 14971 is a mandatory requirement for the medical devices manufacturer (Chan et al. 2012). This paper discusses case study of MPD process. The objectives of study are:

- to get an insight into MPD process,

- to map the existing MPD process of the case under consideration into customized phase gate process,

- to identify risks during five phases of MPD and categorize them based on source of occurrence,
Fig. 1 Medical device classification (NAICS classification represented in graphical form)

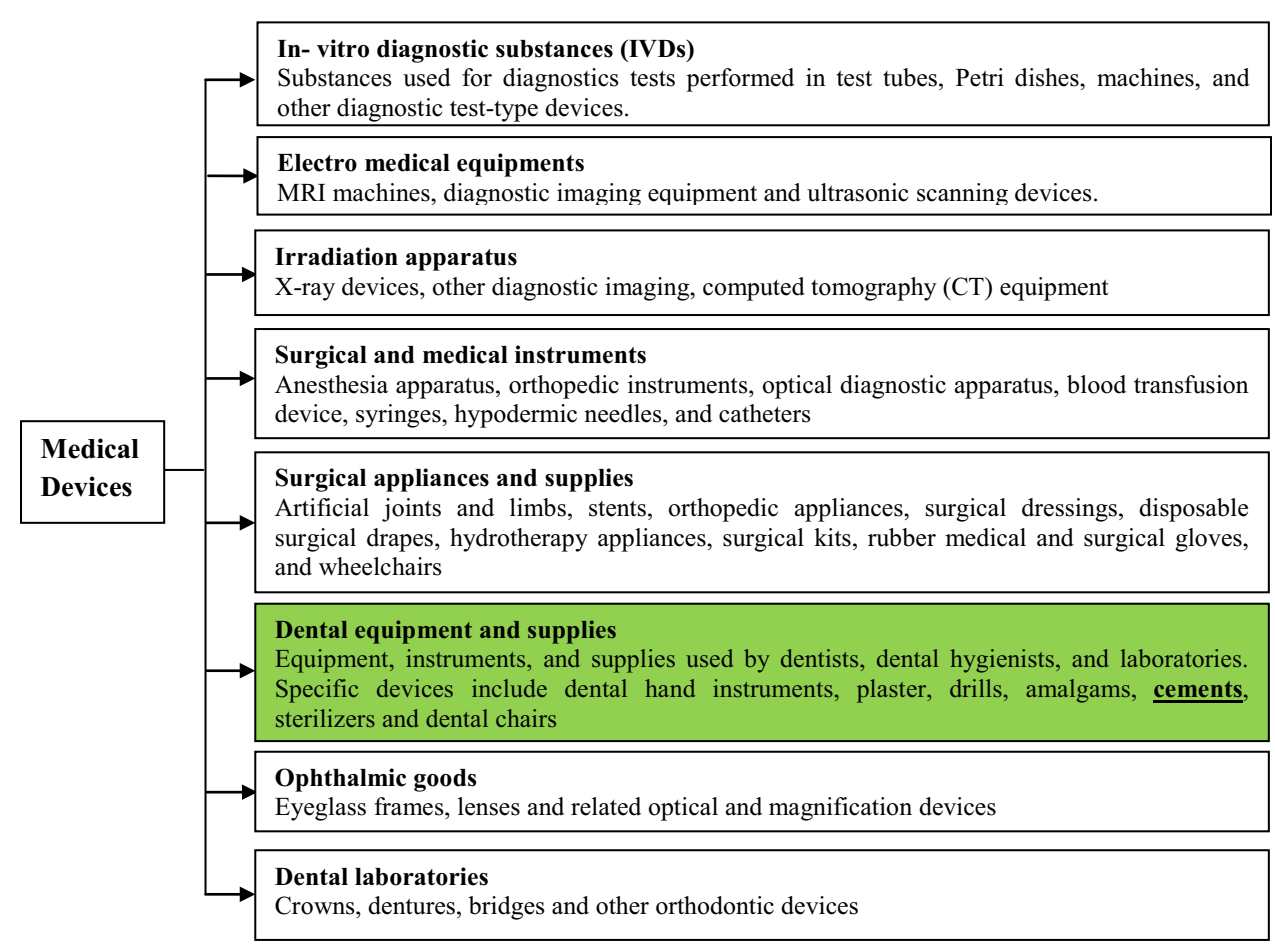


Table 1 Details of the literature referred

\begin{tabular}{lll}
\hline Time period & Search engines and journal database used & Keywords \\
\hline 1990-2013 & Google scholar & Medical product \\
& Springer link & Medical product development \\
Science direct & Medical device \\
ASME & Medical device development \\
Inderscience & Dental product \\
Taylor and Francis & Dental device \\
& Risk \\
& Risk management \\
& Risk mitigation \\
& Risk analysis \\
\hline
\end{tabular}

- to prioritize the risks using traditional FMEA and fuzzy FMEA,

- to compare results of traditional FMEA and fuzzy FMEA,

- to categorize risks based on criticality and propose a risk mitigation plan.

This paper is further organized as follows: section two reviews the literature. Section three details the research methodology adopted. Phase-wise risk identification, ranking and analysis using traditional FMEA and fuzzy FMEA are discussed in section four. Section five presents risk treatments and risk mitigation model. Results, discussion, conclusion and future scope are discussed in section six.

\section{Literature review}

This paper discusses a case of MPD process risk identification, analysis and management in detail. Different authors have carried research work related to risks in other PD and MPD which are discussed here.

\section{Product development process risks}

As compared to MPD risks, risks in other PD have been studied more.

Chalupnik et al. (2009) focused on the approaches which aimed to mitigate the likely impact of process risks on product performance without removing the sources of risks. Browning et al. (2002) specified that the goal of PD process is to produce a recipe that satisfies requirements. They developed a risk value method to integrate approaches as technical performance measure tracking charts and risk reduction profiles. Unger and Eppinger (2011) discussed PD processes and proposed PD process design method. The risk categories and steps for risk management also have been discussed. Zhang and Chu (2011) applied fuzzy Risk priority number (RPN)-based method to ensure the robustness against uncertainty of a new horizontal directional drilling machine. They mentioned that risk analysis is very important in reducing the failures. Tang et al. (2011) developed a risk management framework and applied it to assess customer perception risk in NPD process. Choi and Ahn (2010) proposed a risk analysis model to determine the risk degrees of the risk factors occurring in PD process. They used both fuzzy theory and Markov processes on concurrent engineering basis. Kayis et al. (2006) developed a user interactive, dynamic risk management software package which was commercialized and deployed successfully by a major international manufacturer. Thunnissen (2003) classified the risks and uncertainties in detail. Kayis et al. (2007) identified and quantified the most prominent risks in the product life cycle. They also developed five algorithms for finding the feasible solution for mitigation of the risks. Cooper (2003) presented a practitioner view of the desired characteristics of tools to support NPD and suggested a need to construct a robust risk management framework. The details of the literature reviewed are as shown in Table 1.

\section{Medical product development risks}

A small fault or mistake made in our daily life might not be so severe but in the health care domain, the smallest mistake in development can make the difference between life and death (Lindholm and Host 2009). ISO 14971 is dedicated for RM of medical devices, while United States Food and drug administration (USFDA) strongly implies the link in their quality system regulation. It is a complete guide for RM consisting of several steps. There is sparseness of literature on the development process RM of medical products.

Details of the research related to risks in medical products are given in Table 2.

It is recommended that, RM should be done through PD process (ISO 14971:2012; Schmland 2005). 
Table 2 Details of research related to medical product risks

\begin{tabular}{|c|c|c|}
\hline Risk management process attribute & Event/case & References \\
\hline Residual risk & - & Schmland (2005) \\
\hline Risk analysis & Dental implant & Braceras et al. (2008) \\
\hline Risk identification by: physicians, developers and software developers & $\begin{array}{l}\text { Procurement of a patient monitoring } \\
\text { system }\end{array}$ & $\begin{array}{l}\text { Lindholm and Host } \\
\text { (2009) }\end{array}$ \\
\hline $\begin{array}{l}\text { Medical device failure modes, mechanisms and effect analysis (FMMEA) to identify root } \\
\text { causes and effect mechanisms }\end{array}$ & Infusion pump failure & Cheng et al. (2011) \\
\hline $\begin{array}{l}\text { Risk analysis (ISO 14971) and failure analysis (FMEA) to assure device quality in the design } \\
\text { phase of MPD }\end{array}$ & Ventilation breathing circuit & Chan et al. (2012) \\
\hline Risk assessment using FMEA and fuzzy linguistic theory & $\begin{array}{l}\text { Human reliability assessment of } \\
\text { medical devices }\end{array}$ & Lin et al. (2014) \\
\hline
\end{tabular}

\section{Materials and methods}

This paper has employed a descriptive method, i.e., a case study for research as explained by Yin (1984). The objective of this study is to identify risks during different stages of development of a dental product, i.e., dental cement. The case study method has been selected because for this type of research, direct access to the operational and technical decision makers of the company is required. This facilitates the collection of data through the product developers of the company. The flow of the research work is depicted in Fig. 2.

\section{History}

The case under study has been conducted with a dental manufacturing company who is into existence for more than 10 years. It manufactures total sixteen dental products. The company falls under the category of small and medium sized manufacturing enterprises (SMEs) which are under tremendous pressure due to free market economy, rapid technological development and continuous change in customer demands (Islam and Tedford 2012). In addition to these, medical product manufacturing companies have to fulfill the regulatory requirements.

\section{The product}

The dental cement falls under the category of dental equipment and supplies as per NAICS classification (refer Fig. 1). It is used as a temporary filling to aid recovery of an inflamed pulp. It acts as a protective base beneath the amalgamation restoration. For temporary application, it is used as luting agent for crowns of different materials.

\section{Data collection}

Two methods are used for data collection:

1. Interviews with the development team.

2. Referring the documents such as-technical reports, minutes of meeting, etc.

\section{Analysis}

The detailed analysis of the product under study was carried out. Following points were noted during discussion and the document references:

1. This product was under development since the past 8 months.

2. There were complaints by the end users regarding the performance, hence modifications were undertaken.

It was been regarded as a good candidate to consider as a case to identify important risks during MPD process.

The development team consisted of:

- The managing director of the company.

- Two dentists.

- Two manufacturing engineers.

The existing product development process was studied and is depicted in Fig. 3.

The company was not using any specific model for the development of the product. Probably the same thing what many small and medium medical product manufacturing companies do?

\section{Process mapping}

The next part of the work was to prepare the development team for identification of risks during different phases of MPD. With detailed understanding of the current development process (refer Fig. 3), it was mapped with a five phase process.

\section{Medical product development phases and risk management}

Five phases of MPD are considered (Pietzsch et al. 2009). Lindholm and Host (2009) identified risks using controlled experiments for procurement of medical product. Cagliano et al. (2011) used risk breakdown structure to identify risk sources. This paper identifies the risks involved in MPD process through the expertise of development team 


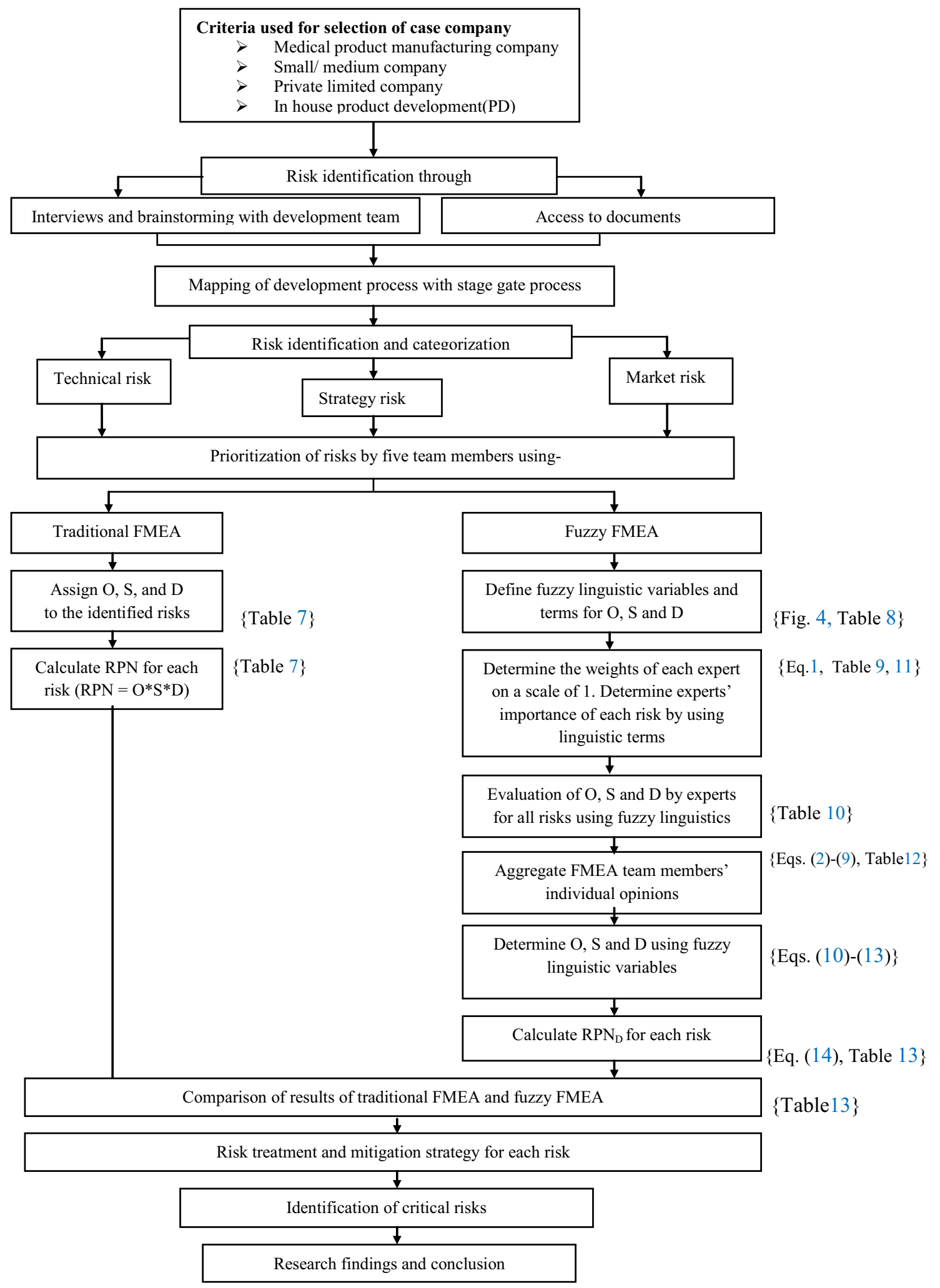

Fig. 2 Methodology used for research 
Fig. 3 Existing process of MPD

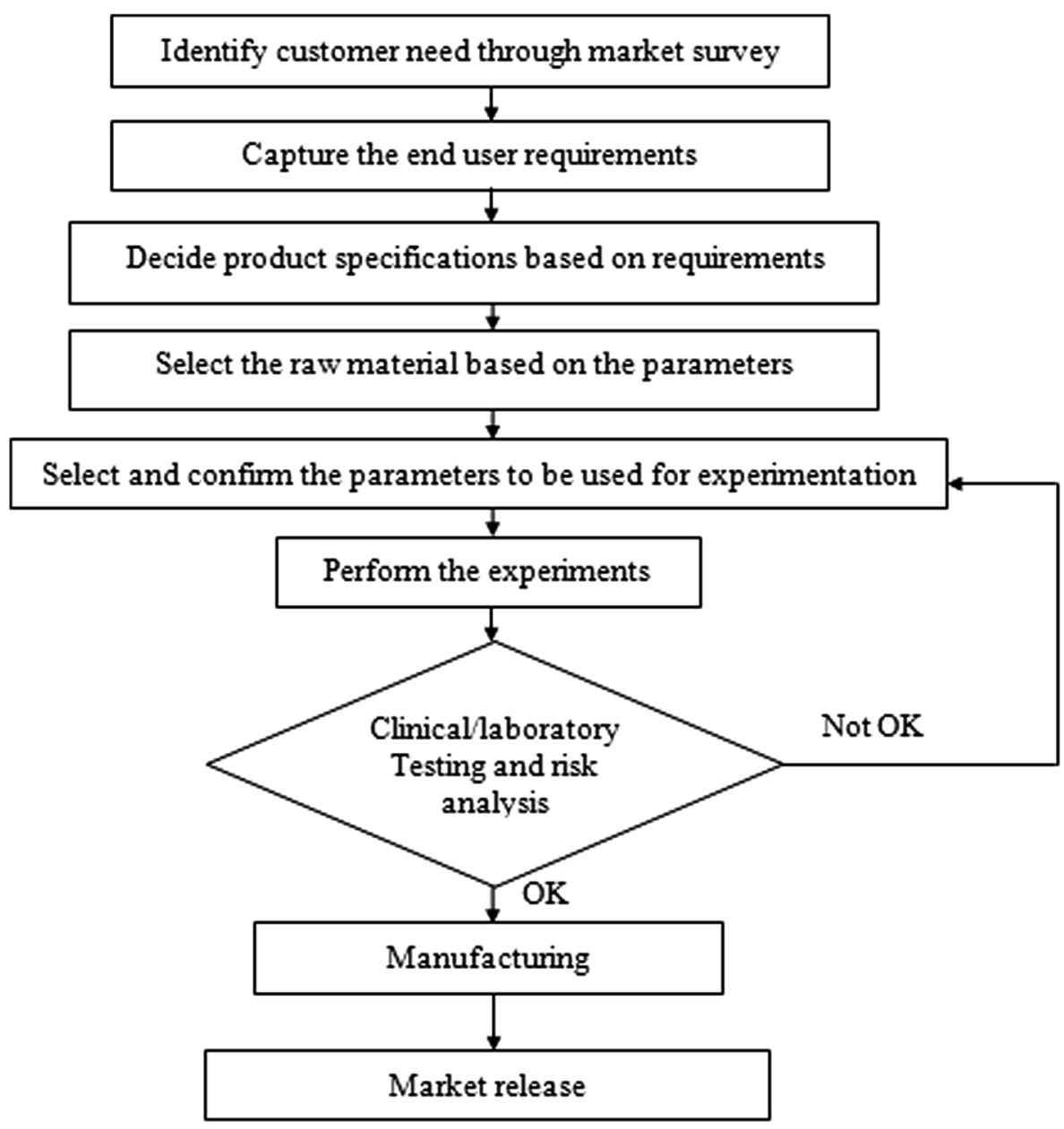

members. The activities at each stage and the associated risks are identified as shown in Table 3 along with the risks identified during each stage.

The risk identification is the most important phase of this work. A total of twenty most prevalent risks during five phases of MPD are identified. These risks are classified into three categories: technical, strategy and market risks. This categorization is done based on the expert's opinion, source of risks and the literature referred (refer Table 4). These categories contribute individually and interactively to the product performance (Mu et al. 2009).

The three categories are described as:

1. Technical risks: the risk of not meeting technical and functional performance requirements, it occurs because of technical uncertainty.

2. Strategy risks: the risks due to operating strategy of the company and are mostly associated with culture and structure of the company.

3. Market risks: even in the absence of risks due to technology when the device fails to satisfy customer needs, it is regarded to as market risk.
Table 5 shows the classification of the risks into three categories and the coding.

It can be seen from Table 5 that the technical risks contribute most to the MPD process, followed by strategy risks and market risks, respectively. This research uses two approaches for risks analysis and prioritization: traditional FMEA and fuzzy FMEA, which are discussed in detail in the next subsections.

\section{Failure mode and effect analysis (FMEA)}

FMEA is a risk assessment tool to evaluate and mitigate the potential failures in systems, processes, designs or services (Lin et al. 2014). It is an effective quality improvement and risk assessment tool (Tay and Lim 2008) widely used in practice (Islam and Tedford 2012). FMEA and ISO 14971 risk analysis receive most attention from manufacturing companies (Chan et al. 2012); therefore, FMEA is used as a prevention and improvement tool to analyze the risks in MPD process. The risk during each stage and the associated consequences related to its occurrence were discussed with 
Table 3 Activities and risks during the phases of medical product development process

\begin{tabular}{|c|c|c|c|}
\hline Sr. no. & Phase & Activities & Risks \\
\hline 1 & Concept & $\begin{array}{l}\text { Capturing customer requirements } \\
\text { Finding alternative concepts } \\
\text { Screening for regulatory strategy } \\
\text { Screening for tooling and fixtures }\end{array}$ & $\begin{array}{l}\text { Ambiguity in capturing the customer requirements } \\
\text { Lack of modeling the captured requirements } \\
\text { Poor evaluation of the requirements in detail } \\
\text { Poor evaluation }\end{array}$ \\
\hline 2 & Architecture & $\begin{array}{l}\text { Formation of core team } \\
\text { Preparing time schedule } \\
\text { Supplier selection and planning } \\
\text { Preparing validation plan }\end{array}$ & $\begin{array}{l}\text { Lack of decomposition of the tasks involved } \\
\text { Poor selection of methods to accomplish the tasks } \\
\text { Mapping of available resources with the required } \\
\text { Poor selection of team members }\end{array}$ \\
\hline 3 & Development & $\begin{array}{l}\text { Deciding design inputs } \\
\text { Planning for manufacturing } \\
\text { Regulatory strategy } \\
\text { Clinical validation studies } \\
\text { Preparing prototypes }\end{array}$ & $\begin{array}{l}\text { Poor design specifications } \\
\text { Lack of planning for manufacturing resources } \\
\text { Poor quality requirements definition } \\
\text { Poor validation strategies }\end{array}$ \\
\hline 4 & Testing & $\begin{array}{l}\text { Prototype evaluation } \\
\text { Product risk analysis } \\
\text { Finalizing process parameters } \\
\text { Continued clinical testing }\end{array}$ & $\begin{array}{l}\text { Wrong selection of design performance parameters } \\
\text { Poor risk management plans } \\
\text { Discontinued clinical testing } \\
\text { Lack of process qualification criteria }\end{array}$ \\
\hline 5 & Validation and launch & $\begin{array}{l}\text { Validation of product } \\
\text { Product launching } \\
\text { Training to dentist/users } \\
\text { Feedback for improvement } \\
\text { Quality audits } \\
\text { Continued clinical validation }\end{array}$ & $\begin{array}{l}\text { Poor product branding and launching strategy } \\
\text { Lack of continuous training to product users } \\
\text { Lack of post-launch quality audits } \\
\text { Discontinued clinical validation }\end{array}$ \\
\hline
\end{tabular}

Table 4 Technical and market risks addressed by researchers

\begin{tabular}{|c|c|c|}
\hline Sr. no. & Risk category & References \\
\hline 1 & Technical risk & $\begin{array}{l}\text { Mikkelsen (1990), Smith (1999); Browning et al. (2002), Saari (2004); } \\
\text { Kayis et al. (2007), Unger and Eppinger (2009) and Unger and } \\
\text { Eppinger (2011) }\end{array}$ \\
\hline 2 & Market risk & $\begin{array}{l}\text { Thunnissen(2003), Saari (2004), Unger and Eppinger (2009), Unger } \\
\text { and Eppinger (2011), Meherjerdi and Dehghenbaghi (2013) and } \\
\text { Song et al.(2013) }\end{array}$ \\
\hline
\end{tabular}

the development team. Calculation of RPNs for identified risks as prescribed by ISO 14971 (2012) guidelines for risk analysis is one noticeable step in FMEA to prioritize the failure modes (Li and Zeng 2014). RPNs are determined by evaluation of three factors: occurrence $(\mathrm{O})$, severity $(\mathrm{S})$ and detection (D) (Zhang and Chu 2011) as discussed here:

\section{- Occurrence $(\mathrm{O})$}

The number of times the risk occurs is called as probability of occurrence.

\section{- Severity (S)}

The effect of each risk on the process is expressed in terms of severity or the level of risk.

- Detection (D)
This ranks the ability of planned tests and inspections to remove defects or detect failure modes in time. The assigned detection number measures the risk that the failure will escape detection. A high detection number indicates that the chances are high that the failure will escape detection or, in other words, that the chances of detection are low.

The three risk factors are evaluated using 10-point scale as described in Table 6. Risks with higher RPN values are assumed to be more important and are given higher priorities over others (Mariajayaprakash et al. 2013). Each potential risk associated with the MPD process is scored in relation to $\mathrm{O}, \mathrm{S}$ and $\mathrm{D}$ (refer Table 7).

The methodology of FMEA is shown in Fig. 2. 
Table 5 Risks coding and categorization based on source of occurrence

\begin{tabular}{llll}
\hline Sr. no. & Risk category & Risk code & Risk under each category \\
\hline 1 & Technical risks & T1 & Lack of modeling the captured requirements \\
& T2 & Poor design specifications \\
& T3 & Lack of planning for manufacturing resources \\
& T4 & Poor definition of quality requirements \\
& T5 & Wrong selection of design performance parameters \\
& T6 & Poor risk management plans \\
& T7 & Discontinued clinical testing \\
& T8 & Lack of process qualification criteria \\
& T9 & Poor validation strategies \\
& S1 & Poor evaluation of the requirements in detail \\
& S2 & Poor evaluation of the intellectual resources available \\
& S3 & Lack of decomposition of the tasks involved \\
& S4 & Poor selection of methods to accomplish the tasks \\
& S5 & Mapping of available resources with the required \\
& S6 & Poor selection of team members \\
& S7 & Lack of post-launch quality audits \\
& S8 & Discontinued clinical validation \\
& M1 & Ambiguity in capturing the customer requirements \\
& M2 & Poor product branding and launching strategy \\
& M3 & Lack of continuous training to product users \\
\hline & &
\end{tabular}

Table 6 Criteria for the probability of occurrence, severity and detection

\begin{tabular}{llll}
\hline Score & Occurrence & Severity & Detection \\
\hline 1 & Very unlikely to occur & Very low-will not affect the process & Certain-fault will be caught on test \\
$2 / 3$ & Unlikely to occur & Low—-may affect the process & High \\
$4 / 5$ & May occur about half of the time & Medium—slightly affect the process & Moderate \\
$6 / 7 / 8$ & Likely to occur & High-mostly affect the process & Low \\
$9 / 10$ & Very likely to occur & Very high-definitely affect the process & Fault will be passed to customer undetected
\end{tabular}

Then, RPN is calculated by multiplying O, S and D. The higher the RPN for a particular factor, the greater is the risk of failure of the process due to that factor.

Based on RPNs, the risks are ranked as shown in Table 7. In spite of extensive use of FMEA for risk analysis, it has been criticized for number of reasons as discussed here:

1. RPN is calculated by multiplication of $\mathrm{O}, \mathrm{S}$ and $\mathrm{D}$. Different combinations of $\mathrm{O}, \mathrm{S}$ and $\mathrm{D}$ have different risk impacts but may produce same value of RPN. This may lead to wastage on the part of resources or time.

2. $\mathrm{O}, \mathrm{S}$ and $\mathrm{D}$ have different relative importance which is not considered in FMEA. The three factors are assumed to be equally important (Vencheh et al. 2013). This may not be always the case in practical situation.

3. Precise evaluation of O, S and D is difficult (Liu et al. 2013).
4. The occurrence $(\mathrm{O})$ score is required to be rated and updated manually from time to time by users based on their knowledge, experience and with reference to the latest data. It makes FMEA tedious and time consuming (Tay and Lim 2008).

5. RPNs are not continuous with many holes (Liu et al.2013).

6. Effectiveness of risk mitigation measures taken cannot be evaluated using RPN.

In addition to these, authors experienced few other issues with traditional FMEA. The experience of experts is not considered while calculating RPNs, which is very important in MPD process where the data regarding $\mathrm{O}, \mathrm{S}$ and $\mathrm{D}$ are based on the FMEA team members' experience. Also asking the experts to assign scores ranging from 1 to 10 for different risks considered may produce false and unrealistic impression (Kumru and Kumru 2013). To overcome the 
Table 7 O, S, D and RPNs for the risks identified by traditional FMEA

\begin{tabular}{|c|c|c|c|c|c|c|c|c|c|c|c|c|c|c|c|c|c|c|c|c|}
\hline & \multicolumn{20}{|c|}{ Risks (failure modes) } \\
\hline & $\mathrm{T} 1$ & $\mathrm{~T} 2$ & $\mathrm{~T} 3$ & $\mathrm{~T} 4$ & $\mathrm{~T} 5$ & $\mathrm{~T} 6$ & $\mathrm{~T} 7$ & $\mathrm{~T} 8$ & T9 & $\mathrm{S} 1$ & $\mathrm{~S} 2$ & $\mathrm{~S} 3$ & $\mathrm{~S} 4$ & S5 & S6 & S7 & S8 & M1 & M2 & M3 \\
\hline \multicolumn{21}{|l|}{ Risk factors } \\
\hline $\mathrm{O}$ & 5 & 6 & 4 & 7 & 3 & 7 & 9 & 7 & 5 & 5 & 4 & 4 & 6 & 7 & 6 & 6 & 7 & 7 & 5 & \\
\hline$S$ & 2 & 9 & 4 & 7 & 7 & 7 & 4 & 6 & 5 & 3 & 3 & 5 & 6 & 6 & 3 & 6 & 7 & 8 & 7 & \\
\hline $\mathrm{D}$ & 2 & 8 & 5 & 5 & 7 & 6 & 6 & 6 & 7 & 2 & 3 & 2 & 4 & 2 & 2 & 6 & 7 & 3 & 8 & 7 \\
\hline RPN & 20 & 432 & 80 & 245 & 147 & 294 & 216 & 252 & 175 & 30 & 36 & 40 & 144 & 84 & 36 & 252 & 343 & 168 & 280 & 140 \\
\hline Risk ranks & 18 & 1 & 14 & 6 & 10 & 3 & 7 & 5 & 8 & 17 & 16 & 15 & 11 & 13 & 16 & 5 & 2 & 9 & 4 & 12 \\
\hline
\end{tabular}

Fig. 4 Fuzzy linguistic scale for $\mathrm{O}, \mathrm{S}$ and $\mathrm{D}$ for MPD process risks (Lin et al. 2013)

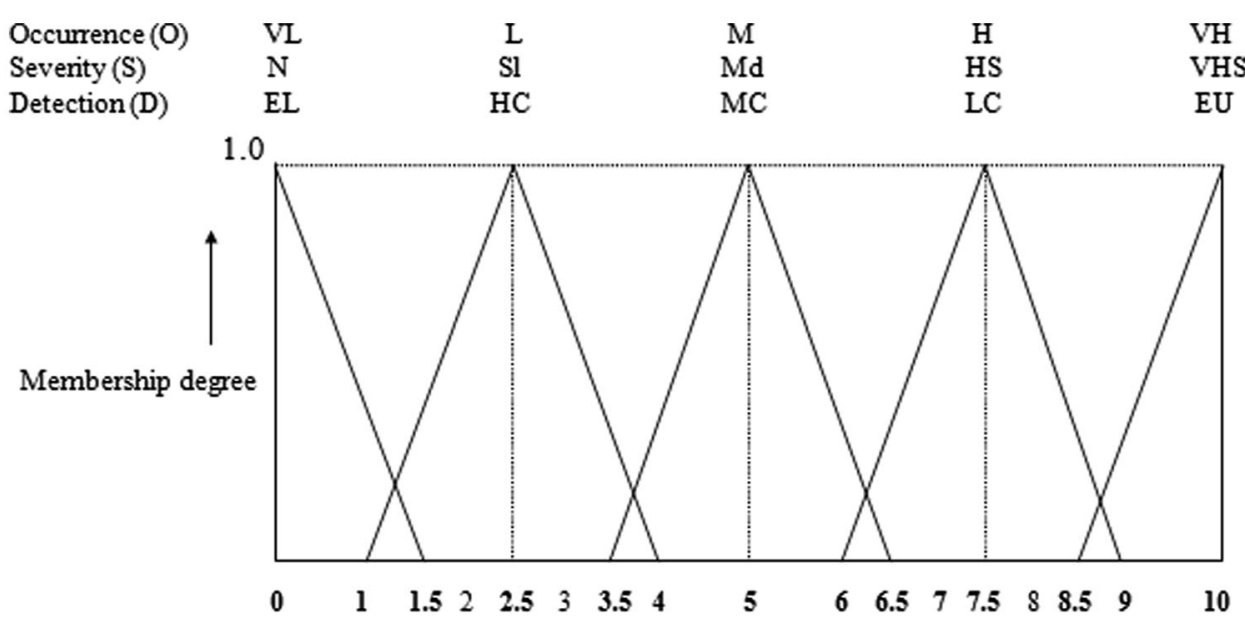

Table 8 Fuzzy linguistics for O, S, D and corresponding fuzzy numbers

\begin{tabular}{|c|c|c|c|c|c|}
\hline \multirow{2}{*}{$\begin{array}{l}\text { Risk factors } \\
\text { Occurrence }\end{array}$} & \multicolumn{5}{|l|}{ Fuzzy linguistic terms } \\
\hline & VL (very low) & L (low) & M (medium) & H (high) & VH (very high) \\
\hline Severity & $\mathrm{N}$ (none) & S1 (slight) & Md (moderate) & HS (high severity) & VHS (very high severity) \\
\hline Detection & $\begin{array}{l}\text { EL (extremely likely } \\
\text { chances of detection) }\end{array}$ & $\begin{array}{l}\text { HC (high chances } \\
\text { of detection) }\end{array}$ & $\begin{array}{l}\text { MC (moderate } \\
\text { chances of } \\
\text { detection) }\end{array}$ & $\begin{array}{l}\text { LC (low chances } \\
\text { of detection) }\end{array}$ & $\begin{array}{l}\text { EU (extremely likely } \\
\text { chances of detection) }\end{array}$ \\
\hline $\begin{array}{l}\text { Corresponding } \\
\text { fuzzy numbers }\end{array}$ & $0,0,1.5$ & $1,2.5,4$ & $3.5,5,6.5$ & $6,7.5,9$ & $8.5,10,10$ \\
\hline
\end{tabular}

drawbacks associated with traditional RPNs, this paper uses fuzzy approach discussed in the next subsection.

\section{Fuzzy FMEA}

Fuzzy linguistic theory has been widely used to solve fuzzy phenomenon problems existing in the real world, such as uncertain, imprecise, unspecific and fuzzy situations. It is a powerful tool for incorporating imprecise data and fuzzy expressions into decision framework (Liu et al. 2014).

In FMEA, O, S and D are three major risk factors considered. Under many practical situations, it is difficult to obtain exact assessment values of the risk factors due to inherent vagueness and uncertainty in human judgments (Liu et al. 2014). Hence, fuzzy approach for FMEA has wide applicability (Liu et al. 2013).

The majority of the fuzzy FMEA approaches use fuzzy if-then rules to prioritize failure modes, which demand a rule base of a very large size based on experts' judgments. Asking an expert to make so many judgments is practically unrealistic. The case considered here is subjective and undefined; the use of fuzzy linguistic is more appropriate. As such, in this research, the linguistic scale with triangular fuzzy numbers (TFNs) is used for the evaluation of $\mathrm{O}, \mathrm{S}$ 
Table 9 Weights of experts

\begin{tabular}{llllll}
\hline Experts & TM1 & TM2 & TM3 & TM4 & TM5 \\
\hline Weights & 0.3 & 0.15 & 0.25 & 0.15 & 0.15 \\
\hline
\end{tabular}

and D (Fig. 4). The description of linguistic and corresponding fuzzy numbers is shown in Table 8 .

The fuzzy $\mathrm{O}, \mathrm{S}$ and $\mathrm{D}$ are based on experience and expertise of team members. The weights of experts are calculated using Eq. (1) as different experts have different influence on the results (Lin et al. 2014).

$w_{\mathrm{tm} k}=\frac{E_{\mathrm{tm} k}}{\sum_{k=1}^{n} E_{\mathrm{tm} k}}, \quad k=1,2,3 \ldots, n$

where $\operatorname{tm} k$ and $E$ are $k$ th team member and its expertise, respectively. The weights of five expert team members are shown in Table 9.

The result of the evaluation of $\mathrm{O}, \mathrm{S}$ and $\mathrm{D}$ of the 20 risks identified during MPD process using fuzzy linguistic terms by five FMEA team members (TM) is shown in Table 10 .

Weight of the importance of each risk has been assigned by experts using fuzzy linguistic terms: unimportant (U), less important (L), medium important (M), important (I) and very important (VI) with corresponding fuzzy numbers $(0,0,0.15),(0.1,0.25,0.4),(0.35,0.5,0.65),(0.6$, $0.75,0.9),(0.85,1,1)$, respectively (Fig. 5 ) (Lin et al. 2013)

Based on experts' opinions, weight of importance of each risk is shown in Table 11.

Let $\mathrm{O}_{i j}^{n}$, $\mathrm{S}_{i j}^{n}$ and $\mathrm{D}_{i j}^{n}$ be the occurrence, severity and detection, respectively, which are evaluated by $n$ experts for interface $i$ and risk $j, \mathrm{O}_{i j}^{n}, \mathrm{~S}_{i j}^{n}$ and $\mathrm{D}_{i j}^{n} \in T$ be the membership function for triangular fuzzy number, $\mathrm{W}_{i j}^{n}$ be the importance weight evaluated by $n$ respondents for interface $i$ and risk $j, \mathrm{~W}_{i j}^{n} \in \mathrm{S}$ be the membership function for it

$\mathrm{O}_{i j}^{n}=\left(\mathrm{OL}_{i j}^{n}, \mathrm{OM}_{i j}^{n}, \mathrm{OU}_{i j}^{n}\right), \quad \mathrm{O}_{i j}^{n} \in T, \quad$ where

$0 \leq \mathrm{OL}_{i j}^{n} \leq \mathrm{OM}_{i j}^{n} \leq \mathrm{OU}_{i j}^{n} \leq 10$

$\mathrm{S}_{i j}^{n}=\left(\mathrm{SL}_{i j}^{n}, \mathrm{SM}_{i j}^{n}, \mathrm{SU}_{i j}^{n}\right), \quad \mathrm{S}_{i j}^{n} \in T, \quad$ where

$0 \leq \mathrm{SL}_{i j}^{n} \leq \mathrm{SM}_{i j}^{n} \leq \mathrm{SU}_{i j}^{n} \leq 10$

$\mathrm{D}_{i j}^{n}=\left(\mathrm{DL}_{i j}^{n}, \mathrm{DM}_{i j}^{n}, \mathrm{DU}_{i j}^{n}\right), \quad \mathrm{D}_{i j}^{n} \in T, \quad$ where

$0 \leq \mathrm{DL}_{i j}^{n} \leq \mathrm{DM}_{i j}^{n} \leq \mathrm{DU}_{i j}^{n} \leq 10$

$\mathrm{W}_{i j}^{n}=\left(\mathrm{WL}_{i j}^{n}, \mathrm{WM}_{i j}^{n}, \mathrm{WU}_{i j}^{n}\right), \quad \mathrm{W}_{i j}^{n} \in \mathrm{S}, \quad$ where

$0 \leq \mathrm{WL}_{i j}^{n} \leq \mathrm{WM}_{i j}^{n} \leq \mathrm{WU}_{i j}^{n} \leq 1$

$\mathrm{O}_{i j}=\mathrm{O}_{i j}^{1} \times W_{\mathrm{tm} 1}+\mathrm{O}_{i j}^{2} \times \mathrm{W}_{\mathrm{tm} 2}+\cdots+\mathrm{O}_{i j}^{n} \times \mathrm{W}_{\mathrm{tm} n}$

$\mathrm{S}_{i j}=\mathrm{S}_{i j}^{1} \times \mathrm{W}_{\mathrm{tm} 1}+\mathrm{S}_{i j}^{2} \times \mathrm{W}_{\mathrm{tm} 2}+\cdots+\mathrm{S}_{i j}^{n} \times \mathrm{W}_{\mathrm{tm} n}$

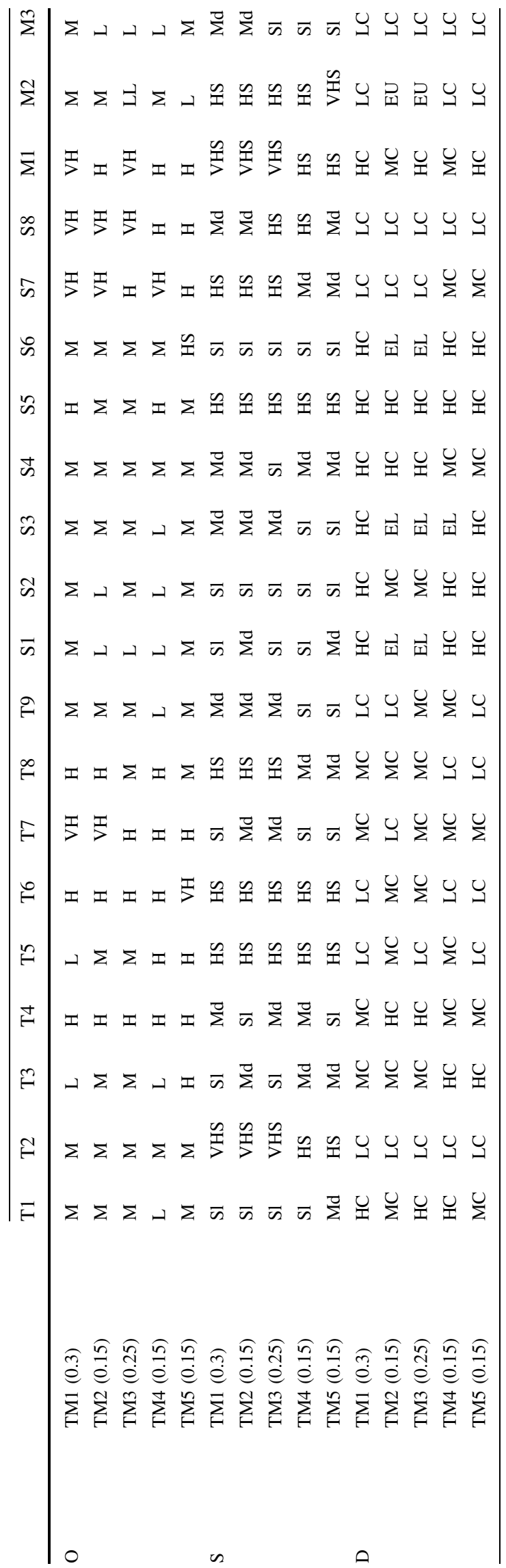


Fig. 5 Fuzzy linguistic scale for weight of importance of each risk (Lin et al. 2013)
Unimportant

(U)
Less

important (L)
Medium important

(M)
Important

(I)
Very important (VI)

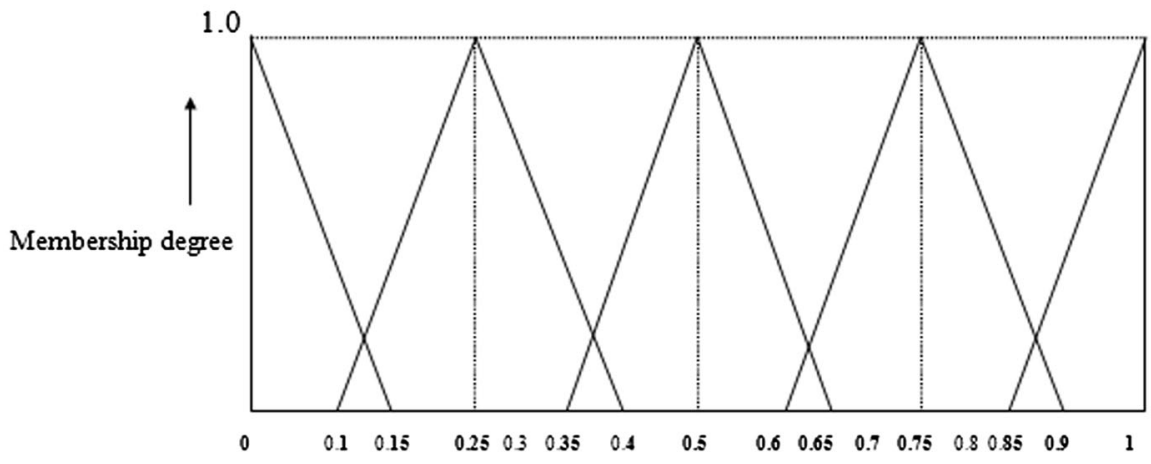

Table 11 Weight of importance of each risk assigned by team members

\begin{tabular}{|c|c|c|c|c|c|c|c|c|c|c|c|c|c|c|c|c|c|c|c|c|}
\hline \multirow[t]{2}{*}{ FMEA team member } & \multicolumn{20}{|c|}{ Risks } \\
\hline & $\mathrm{T} 1$ & $\mathrm{~T} 2$ & $\mathrm{~T} 3$ & $\mathrm{~T} 4$ & $\mathrm{~T} 5$ & T6 & $\mathrm{T} 7$ & $\mathrm{~T} 8$ & T9 & S1 & S2 & $\mathrm{S} 3$ & S4 & S5 & S6 & S7 & S8 & M1 & M2 & M3 \\
\hline TM1 (0.3) & I & VI & M & VI & VI & VI & I & M & VI & $\mathrm{L}$ & $\mathrm{L}$ & $\mathrm{L}$ & M & $\mathrm{L}$ & $\mathrm{L}$ & M & VI & I & I & $\mathrm{L}$ \\
\hline TM2 (0.15) & M & VI & $\mathrm{L}$ & VI & I & I & M & $\mathrm{L}$ & I & $\mathrm{L}$ & $\mathrm{L}$ & $\mathrm{L}$ & $\mathrm{L}$ & $\mathrm{L}$ & M & I & I & M & I & $\mathrm{L}$ \\
\hline TM3 (0.25) & VI & VI & I & VI & VI & VI & I & M & I & $\mathrm{L}$ & $\mathrm{L}$ & $\mathrm{L}$ & M & M & I & M & I & M & I & $\mathrm{M}$ \\
\hline TM4 (0.15) & I & VI & $\mathrm{M}$ & I & I & I & I & $\mathrm{L}$ & I & M & $\mathrm{L}$ & $\mathrm{L}$ & $\mathrm{L}$ & M & $\mathrm{L}$ & M & I & I & I & M \\
\hline TM5 (0.15) & I & VI & $\mathrm{M}$ & I & VI & VI & VI & $\mathrm{L}$ & $\mathrm{M}$ & $\mathrm{L}$ & $\mathrm{L}$ & $\mathrm{L}$ & M & $\mathrm{L}$ & M & M & VI & I & I & $\mathrm{L}$ \\
\hline
\end{tabular}

Table 12 Aggregated fuzzy information for twenty risks

\begin{tabular}{|c|c|c|c|c|c|c|c|c|c|c|c|c|}
\hline & \multicolumn{3}{|l|}{$\mathrm{O}$} & \multicolumn{3}{|l|}{$\mathrm{S}$} & \multicolumn{3}{|l|}{ D } & \multicolumn{3}{|l|}{ W } \\
\hline & $\mathrm{OL}_{j}$ & $\mathrm{OM}_{j}$ & $\mathrm{OU}_{j}$ & $\mathrm{SL}_{j}$ & $\mathrm{SM}_{j}$ & $\mathrm{SU}_{j}$ & $\mathrm{DL}_{j}$ & $\mathrm{DM}_{j}$ & $\mathrm{DU}_{j}$ & $\mathrm{WL}_{j}$ & $\mathrm{WM}_{j}$ & $\mathrm{WU}_{j}$ \\
\hline $\mathrm{T} 1$ & 3.125 & 4.625 & 6.125 & 1.375 & 2.875 & 4.375 & 1.75 & 3.25 & 4.75 & 0.625 & 0.775 & 0.8875 \\
\hline $\mathrm{T} 2$ & 3.5 & 5 & 6.5 & 7.75 & 9.25 & 9.7 & 6 & 7.5 & 9 & 0.85 & 1 & 1 \\
\hline $\mathrm{T} 3$ & 2.75 & 4.25 & 5.75 & 2.125 & 3.625 & 5.125 & 2.75 & 4.25 & 5.75 & 0.375 & 0.525 & 0.675 \\
\hline $\mathrm{T} 4$ & 6 & 7.5 & 9 & 2.75 & 4.25 & 5.75 & 2.5 & 4 & 5.5 & 0.775 & 0.925 & 0.97 \\
\hline T5 & 3.5 & 5 & 6.5 & 6 & 7.5 & 9 & 5.25 & 6.75 & 8.25 & 0.775 & 0.925 & 0.97 \\
\hline T6 & 6.375 & 7.875 & 9.15 & 6 & 7.5 & 9 & 5 & 6.5 & 8 & 0.775 & 0.925 & 0.97 \\
\hline $\mathrm{T} 7$ & 7.125 & 8.625 & 9.45 & 2 & 3.5 & 5 & 3.875 & 5.375 & 6.875 & 0.6 & 0.75 & 0.8775 \\
\hline T8 & 5 & 6.5 & 8 & 5.25 & 6.75 & 8.25 & 4.25 & 5.75 & 7.25 & 0.2375 & 0.3875 & 0.5375 \\
\hline T9 & 3.125 & 4.625 & 6.125 & 2.75 & 4.25 & 5.75 & 5 & 6.5 & 8 & 0.6375 & 0.7875 & 0.8925 \\
\hline S1 & 2.125 & 3.625 & 5.125 & 1.75 & 3.25 & 4.75 & 0.6 & 1.5 & 3 & 0.1375 & 0.2875 & 0.4375 \\
\hline $\mathrm{S} 2$ & 2.75 & 4.25 & 5.75 & 1 & 2.5 & 4 & 2 & 3.5 & 5 & 0.1 & 0.25 & 0.4 \\
\hline S3 & 3.125 & 4.625 & 6.125 & 2.75 & 4.25 & 5.75 & 0.45 & 1.125 & 2.625 & 0.1 & 0.25 & 0.4 \\
\hline S4 & 3.5 & 5 & 6.5 & 2.875 & 4.375 & 5.875 & 1.75 & 3.25 & 4.75 & 0.275 & 0.425 & 0.575 \\
\hline S5 & 4.625 & 6.125 & 7.625 & 6 & 7.5 & 9 & 1 & 2.5 & 4 & 0.2 & 0.35 & 0.5 \\
\hline S6 & 3.875 & 5.375 & 6.875 & 1 & 2.5 & 4 & 0.6 & 1.5 & 3 & 0.3 & 0.45 & 0.6 \\
\hline S7 & 7.5 & 9 & 9.6 & 5.25 & 6.75 & 8.25 & 5.25 & 6.75 & 8.25 & 0.3875 & 0.5375 & 0.6875 \\
\hline S8 & 7.75 & 9.25 & 9.7 & 4.5 & 6 & 7.5 & 6 & 7.5 & 9 & 0.7125 & 0.8625 & 0.945 \\
\hline M1 & 7.375 & 8.875 & 9.55 & 7.75 & 9.25 & 9.7 & 1.75 & 3.25 & 4.75 & 0.5 & 0.65 & 0.8 \\
\hline M2 & 2.5 & 4 & 5.5 & 6.375 & 7.875 & 9.15 & 7 & 8.5 & 9.4 & 0.6 & 0.75 & 0.9 \\
\hline M3 & 2.125 & 3.625 & 5.125 & 2.125 & 3.625 & 5.125 & 6 & 7.5 & 9 & 0.2 & 0.35 & 0.5 \\
\hline
\end{tabular}


Table $13 \mathrm{RPN}_{\mathrm{D}}$ values for all risks

\begin{tabular}{|c|c|c|c|c|c|}
\hline Risk code & Risks & $\begin{array}{l}\text { RPN by traditional } \\
\text { FMEA }\end{array}$ & Rank & $\begin{array}{l}\text { RPN by fuzzy FMEA } \\
\left(\mathrm{RPN}_{\mathrm{D}}\right)\end{array}$ & Rank \\
\hline $\mathrm{T} 1$ & Lack of modeling the captured requirements & 20 & 18 & 32.95132 & 15 \\
\hline $\mathrm{T} 2$ & Poor design specifications & 432 & 1 & 317.0625 & 3 \\
\hline $\mathrm{T} 3$ & Lack of planning for manufacturing resources & 80 & 14 & 34.3752 & 14 \\
\hline $\mathrm{T} 4$ & Poor definition of quality requirements & 245 & 6 & 113.475 & 9 \\
\hline T5 & Wrong selection of design performance parameters & 147 & 10 & 225.2813 & 4 \\
\hline T6 & Poor risk management plans & 294 & 3 & 338.4225 & 1 \\
\hline $\mathrm{T} 7$ & Discontinued clinical testing & 216 & 7 & 117.3336 & 8 \\
\hline $\mathrm{T} 8$ & Lack of process qualification criteria & 252 & 5 & 97.75898 & 11 \\
\hline T9 & Poor validation strategies & 175 & 8 & 98.69895 & 10 \\
\hline S1 & Poor evaluation of the requirements in detail & 30 & 17 & 5.758086 & 20 \\
\hline S2 & Poor evaluation of the intellectual resources available & 36 & 16 & 9.296875 & 18 \\
\hline S3 & Lack of decomposition of the tasks involved & 40 & 15 & 6.879688 & 19 \\
\hline S4 & Poor selection of methods to accomplish the tasks & 144 & 11 & 30.21484 & 16 \\
\hline S5 & Mapping of available resources with the required & 84 & 13 & 40.19531 & 12 \\
\hline S6 & Poor selection of team members & 36 & 16 & 10.27969 & 17 \\
\hline S7 & Lack of post-launch quality audits & 252 & 5 & 213.0616 & 5 \\
\hline S8 & Discontinued clinical validation & 343 & 2 & 336.42 & 2 \\
\hline M1 & Ambiguity in capturing the customer requirements & 168 & 9 & 161.6908 & 7 \\
\hline M2 & Poor product branding and launching strategy & 280 & 4 & 194.22 & 6 \\
\hline M3 & Lack of continuous training to product users & 140 & 12 & 34.49414 & 13 \\
\hline
\end{tabular}

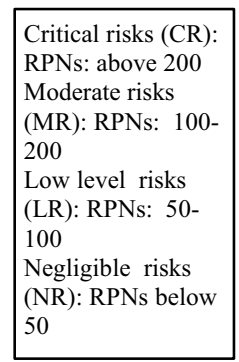

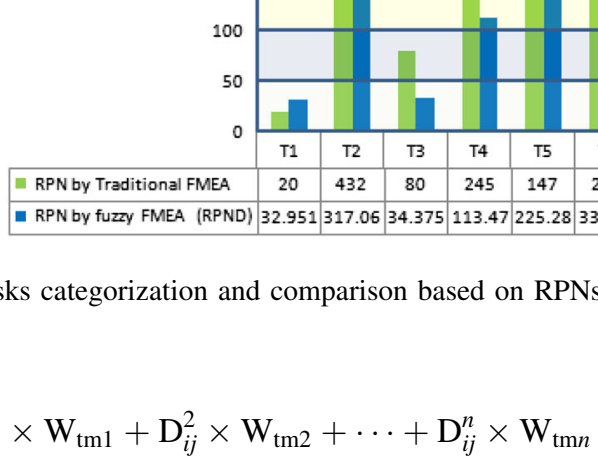

$$
\begin{aligned}
& \mathrm{W}_{i j}=\mathrm{W}_{i j}^{1} \times \mathrm{W}_{\mathrm{tm} 1}+\mathrm{W}_{i j}^{2} \times \mathrm{W}_{\mathrm{tm} 2}+\cdots+\mathrm{W}_{i j}^{n} \times \mathrm{W}_{\mathrm{tm} n}
\end{aligned}
$$

where $\mathrm{O}_{i j}, \mathrm{~S}_{i j}, \mathrm{D}_{i j}$ are occurrence, severity and detection values of experts' team members opinion for interface $i$ and risk $j, \mathrm{~W}_{i j}$ is importance for each risk evaluated by experts' team members for interface $j$ and risk $j i, \mathrm{~W}_{\mathrm{tm} k}$ is the weight of $k$ th team member and $n$ is the number of experts' team members, respectively.
The fuzzy numbers for probability of occurrence (O), severity (S), detection (D) and fuzzy weights for each risk by each team member (W) are aggregated based on expert team members' subjective opinion using Eqs. (6)-(9) (Lin et al. 2013). The aggregated fuzzy information for twenty risks is shown in Table 12.

The values shown in Table 12 for twenty risks in MPD process are fuzzy sets. Defuzzification of the fuzzy sets is necessary to convert the fuzzy sets into numerical values. 


\begin{tabular}{|c|c|c|c|c|c|c|c|c|c|c|}
\hline & \multicolumn{2}{|c|}{ Concept } & \multicolumn{2}{|c|}{ Architecture } & \multicolumn{2}{|c|}{ Development } & \multicolumn{2}{|c|}{ Testing } & \multicolumn{2}{|c|}{ Validation and launch } \\
\hline & FMEA & $\begin{array}{l}\text { Fuzzy } \\
\text { FMEA }\end{array}$ & FMEA & $\begin{array}{l}\text { Fuzzy } \\
\text { FMEA }\end{array}$ & FMEA & $\begin{array}{l}\text { Fuzzy } \\
\text { FMEA }\end{array}$ & FMEA & $\begin{array}{l}\text { Fuzzy } \\
\text { FMEA }\end{array}$ & FMEA & $\begin{array}{l}\text { Fuzzy } \\
\text { FMEA }\end{array}$ \\
\hline CR & & & & & $\begin{array}{l}\text { T2 } \\
\text { T4 }\end{array}$ & $\mathrm{T} 2$ & $\begin{array}{l}\text { T6 } \\
\text { T7 } \\
\text { T8 } \\
\end{array}$ & $\begin{array}{l}\text { T5 } \\
\text { T6 }\end{array}$ & $\begin{array}{c}\text { S7 } \\
\text { S8 } \\
\text { M2 }\end{array}$ & $\begin{array}{l}\text { S7 } \\
\text { S8 }\end{array}$ \\
\hline MR & M1 & M1 & S4 & & T9 & T4 & T5 & $\mathrm{T7}$ & M3 & M2 \\
\hline LR & & & S5 & & T3 & & & T8 & & T9 \\
\hline NR & $\begin{array}{l}\mathrm{T} 1 \\
\mathrm{~S} 1 \\
\mathrm{~S} 2\end{array}$ & $\begin{array}{l}\mathrm{T} 1 \\
\mathrm{~S} 1 \\
\mathrm{~S} 2\end{array}$ & $\begin{array}{l}\text { S3 } \\
\text { S6 }\end{array}$ & $\begin{array}{l}\text { S3 } \\
\text { S4 } \\
\text { S5 } \\
\text { S6 }\end{array}$ & & T3 & & & & M3 \\
\hline
\end{tabular}

Fig. 7 Phase-wise scatter of risks based on category and severity

There are different algorithms for defuzzification, such as centre of gravity, centre of gravity for singletons, centre of area, left most maximum, right most maximum (Kumru and Kumru 2013) and mean of maximum. As compared to Mean of maximum (MoM), Centre of Area (CoA) yields better results (Lin et al. 2014). Fuzzy occurrence, severity, detection and fuzzy weight of importance of each risk in MPD process have been calculated using Eqs. (10)-(13) (Lin et al. 2013), respectively.

$\mathrm{DO}_{k}=\frac{\left[\left(\mathrm{OU}_{k}-\mathrm{OL}_{k}\right)+\left(\mathrm{OM}_{k}-\mathrm{OL}_{k}\right)\right]}{3}+\mathrm{OL}_{k} \quad \forall k$
$\mathrm{DS}_{k}=\frac{\left[\left(\mathrm{SU}_{k}-\mathrm{SL}_{k}\right)+\left(\mathrm{SM}_{k}-\mathrm{SL}_{k}\right)\right]}{3}+\mathrm{SL}_{k} \quad \forall k$
$\mathrm{DD}_{k}=\frac{\left[\left(\mathrm{DU}_{k}-\mathrm{DL}_{k}\right)+\left(\mathrm{DM}_{k}-\mathrm{DL}_{k}\right)\right]}{3}+\mathrm{DL}_{k} \quad \forall k$
$\mathrm{DW}_{k}=\frac{\left[\left(\mathrm{WU}_{k}-\mathrm{WL}_{k}\right)+\left(\mathrm{WM}_{k}-\mathrm{WL}_{k}\right)\right]}{3}+\mathrm{WL}_{k} \quad \forall k$

$\mathrm{RPN}_{\mathrm{D}}$ is calculated using $\mathrm{DO}_{k}, \mathrm{DS}_{k}, \mathrm{DD}_{k}$ and $\mathrm{DW}_{k}$.

$\mathrm{RPN}_{\mathrm{D}}=\mathrm{DO}_{k} \times \mathrm{DS}_{k} \times \mathrm{DD}_{k} \times \mathrm{DW}_{k}$

Table 13 shows the $\mathrm{RPN}_{\mathrm{D}}$ values for all twenty risks identified during MPD process using Eq. (14) (Lin et al. 2013).

A comparison of RPN by traditional FMEA and $\mathrm{RPN}_{\mathrm{D}}$ obtained by fuzzy FMEA is shown in Table 13. After doing the comparative analysis of the risks identified during MPD process using Traditional FMEA and Fuzzy FMEA, it is found that later has some advantages as compared to traditional FMEA (Liu et al. 2013):

- Complex and ambiguous data can be handled in a consistent manner for risk assessment.

- Risk evaluation function can be customized based on the nature of process.

- Combination of three factors, $\mathrm{O}, \mathrm{S}$ and $\mathrm{D}$, of risks in more flexible and realistic way is possible.
At the same time, it has some drawbacks as discussed here (Liu et al. 2013):

- To define appropriate membership function, risk factor is a crucial task.

- Any modification in the number of linguistic scale and terms requires redefinition of membership functions.

- User has to deal with complex calculations to draw the inferences.

- Even when their membership functions overlap, they provide arbitrary priority ranks of failure modes (Mandal and Maiti 2014).

After calculating RPNs using traditional FMEA and fuzzy FMEA, the risks during MPD process are categorized as: critical risks (CR), moderate risks (MR), low level risks (LR) and negligible risks (NR) based on the RPNs calculated and their criticality.

The detailed categorization and comparison of risks are shown in Fig. 6. The limits of RPNs for categorization are set based on experts' opinions.

\section{Mapping risks to the MPD phases}

After carrying the detailed analysis of the risks identified, the risks are mapped back to the five phases of MPD process. A phase-wise comparison between the results of traditional FMEA and fuzzy FMEA based on their category and severity is shown in Fig. 7.

\section{Risk mitigation}

The next step in the risk management is to suggest risk mitigation strategy for the identified risks. As a result of brainstorming and discussion with the MPD experts, the risk treatment for each risk and the mitigation strategy for each category of criticality are recommended as shown in Table 14. 
Table 14 Risk treatments and mitigation strategies recommended

\begin{tabular}{|c|c|c|c|}
\hline $\begin{array}{l}\text { Risk } \\
\text { category }\end{array}$ & Risks & Risk treatments suggested & $\begin{array}{l}\text { Risk mitigation strategy } \\
\text { recommended }\end{array}$ \\
\hline \multirow{11}{*}{$\begin{array}{l}\text { Critical } \\
\text { risks }(\mathrm{CR})\end{array}$} & $\mathrm{T} 2$ poor design Specifications & Detailed documentation of the design & \multirow{11}{*}{$\begin{array}{l}\text { Prepare and implement risk response } \\
\text { plan immediately }\end{array}$} \\
\hline & \multirow{2}{*}{$\begin{array}{l}\text { S8 discontinued clinical } \\
\text { validation }\end{array}$} & Mention criteria for acceptance of validation & \\
\hline & & $\begin{array}{l}\text { Clinical validation should be continued, the period } \\
\text { for the same should be determined }\end{array}$ & \\
\hline & \multirow[t]{2}{*}{ T6 poor risk management plans } & $\begin{array}{l}\text { Decide the decision making points in risk } \\
\text { management }\end{array}$ & \\
\hline & & $\begin{array}{l}\text { Decompose the risks into categories and prepare plan } \\
\text { in detail }\end{array}$ & \\
\hline & \multirow{2}{*}{$\begin{array}{l}\text { S7 lack of post-launch quality } \\
\text { audits }\end{array}$} & The quality audit points should be pre-decided & \\
\hline & & $\begin{array}{l}\text { The criteria for acceptance at each point should be } \\
\text { decided }\end{array}$ & \\
\hline & $\begin{array}{l}\text { T8 lack of process qualification } \\
\text { criteria }\end{array}$ & $\begin{array}{l}\text { A clear process qualification criteria should be } \\
\text { specified }\end{array}$ & \\
\hline & $\begin{array}{l}\mathrm{T} 4 \text { poor definition of quality } \\
\text { requirements }\end{array}$ & The quality at each stage must be clearly defined & \\
\hline & \multirow{2}{*}{$\begin{array}{l}\text { M1 ambiguity in capturing the } \\
\text { customer requirements }\end{array}$} & Clear definition of the customer and end user & \\
\hline & & Requirements should be grasped in detail & \\
\hline \multirow[t]{8}{*}{$\begin{array}{l}\text { Moderate } \\
\text { risks (MR) }\end{array}$} & $\begin{array}{l}\text { M2 poor product branding and } \\
\text { launching strategy }\end{array}$ & Experts should be involved to finalize the strategy & $\begin{array}{l}\text { Take action within a short period of } \\
\text { time to avoid future risks }\end{array}$ \\
\hline & T7 discontinued clinical testing & $\begin{array}{l}\text { Clinical testing period should be specified based on } \\
\text { the technicalities involved in product }\end{array}$ & \\
\hline & T9 poor validation strategies & $\begin{array}{l}\text { Standard strategies and methods should be adapted } \\
\text { for validation }\end{array}$ & $\begin{array}{l}\text { Keep a track and make preventive } \\
\text { action plan }\end{array}$ \\
\hline & \multirow{2}{*}{$\begin{array}{l}\text { T5 wrong selection of design } \\
\text { performance parameters }\end{array}$} & Design stages should be pre-defined. & \multirow{2}{*}{$\begin{array}{l}\text { Take action within a short period of } \\
\text { time to avoid future risks }\end{array}$} \\
\hline & & $\begin{array}{l}\text { Inputs and expected outcome at each stage should be } \\
\text { specified }\end{array}$ & \\
\hline & $\begin{array}{l}\text { M3 lack of continuous training to } \\
\text { product users }\end{array}$ & Additional user training should be provided & $\begin{array}{l}\text { Keep a track and make preventive } \\
\text { action plan }\end{array}$ \\
\hline & \multirow[t]{2}{*}{$\begin{array}{l}\text { S4 poor selection of methods to } \\
\text { accomplish the tasks }\end{array}$} & $\begin{array}{l}\text { Study of appropriate methods and their application is } \\
\text { necessary }\end{array}$ & \\
\hline & & Additional training on methods should be provided & \\
\hline \multirow[t]{7}{*}{$\begin{array}{l}\text { Low level } \\
\text { risks (LR) }\end{array}$} & $\begin{array}{l}\text { T3 lack of planning for } \\
\text { manufacturing resources }\end{array}$ & $\begin{array}{l}\text { Manufacturing planning and monitoring should be } \\
\text { done }\end{array}$ & $\begin{array}{l}\text { Keep a track and make preventive } \\
\text { action plan }\end{array}$ \\
\hline & $\begin{array}{l}\text { S3 lack of decomposition of the } \\
\text { tasks involved }\end{array}$ & Decompose the task logically and categorically & $\begin{array}{l}\text { Accept the risk actively and take the } \\
\text { corrective action }\end{array}$ \\
\hline & \multirow[t]{2}{*}{$\begin{array}{l}\text { S2 poor evaluation of the } \\
\text { intellectual resources available }\end{array}$} & $\begin{array}{l}\text { Complete know how of the available intellectual } \\
\text { resources is required }\end{array}$ & \\
\hline & & Capabilities of all resources should be known & \\
\hline & $\begin{array}{l}\text { S6 poor selection of team } \\
\text { members }\end{array}$ & $\begin{array}{l}\text { Based on the stage wise requirements of the product, } \\
\text { the team should be formed }\end{array}$ & \\
\hline & $\begin{array}{l}\text { S1 poor evaluation of the } \\
\text { requirements in detail }\end{array}$ & $\begin{array}{l}\text { The actual requirements and their mapping with the } \\
\text { product requirements should be done }\end{array}$ & \\
\hline & $\begin{array}{l}\text { S5 mapping of available } \\
\text { resources with the required }\end{array}$ & $\begin{array}{l}\text { All the resources available and required should be } \\
\text { mapped with each other }\end{array}$ & \\
\hline $\begin{array}{l}\text { Negligible } \\
\text { risk (NR) }\end{array}$ & $\begin{array}{l}\mathrm{T} 1 \text { lack of modeling the captured } \\
\text { requirements }\end{array}$ & $\begin{array}{l}\text { Modeling of the requirements should be done to } \\
\text { optimize the resources and outcomes }\end{array}$ & $\begin{array}{l}\text { Take action if consequences occur } \\
\text { again in future }\end{array}$ \\
\hline
\end{tabular}

\section{Risk mitigation model}

A risk mitigation model is developed (Fig. 8) based on the risks identified and the mitigation strategy suggested. The model has a logical flow. MPD process risks are shown on right-hand side of the model. Critical, moderate, low level and negligible risks are represented in convergent manner as per the severity of occurrence. The area covered by each 
Fig. 8 MPD process risks mitigation model

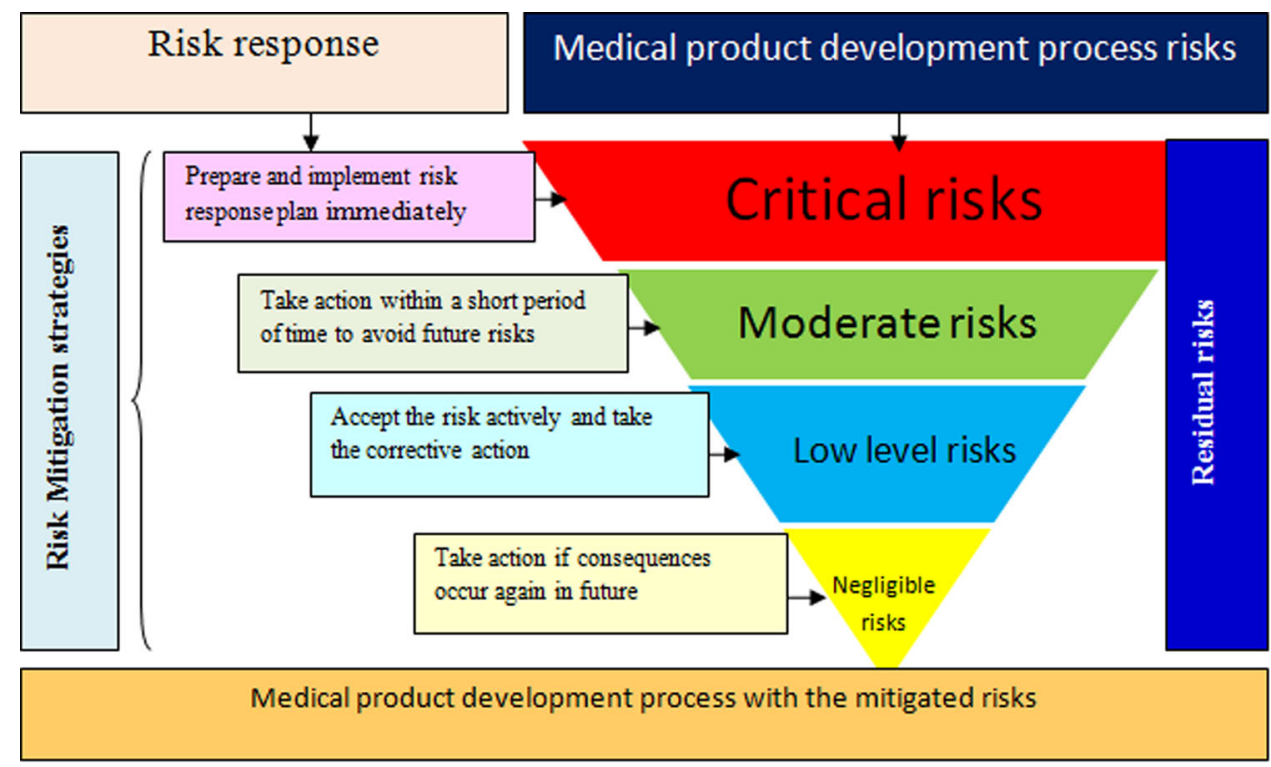

risk is proportional to the severity. Common risk mitigation strategies for risks of different category based on criticality are shown on left-hand side of the model. Residual risks are shown in the model, which still remain after applying the mitigation strategy. The acceptable level of each residual risk should be calculated and decision may be taken based on the severity of the residual risk.

Though the model discussed here is specific for the case considered, it will be useful for any other industry for the purpose of risk mitigation.

\section{Results and discussion}

The risk management methodologies refer to a standard process presenting the well-known steps: risk identification, risk evaluation and quantification, risk mitigation for treatment and/or impact minimization and risk monitoring (Marmier et al. 2013). Most of the research on RM has focused on risk identification and analysis.

A case study of undefined and subjective MPD, i.e., dental cement, is presented here. The existing MPD process is mapped with the standard phase gate process with necessary customization. A total of twenty risks are explored during five phases of the MPD. These risks are categorized as: technical, strategy and market risks based on the source of occurrence. RPN for each risk is calculated using traditional FMEA and fuzzy FMEA; their results are compared. The risks are further categorized as critical, moderate, low level and negligible risks based on their RPN and the criticality. The risks are mapped back to the five phases of development process to know the sources and criticality of different risks along each phase.
Traditional FMEA gives $40 \%$ CRs, $20 \%$ MRs, $10 \%$ LRs and $25 \%$ NRs out of total risks (Fig. 9). During concept phase, $10 \%$ of risks are MRs and $15 \%$ are NRs. Architecture Phase has $5 \%$ of MR, LR each and $10 \%$ NRs. Development phase has $10 \%$ CRs, $5 \%$ MR and LR each. During testing, $15 \%$ are CRs and $5 \%$ MR. Last phase has $15 \%$ CRs and $5 \%$ MR (Fig. 10).

Fuzzy FMEA resulted in $25 \%$ CRs, $20 \%$ MRs, $10 \%$ LRs and $45 \%$ NRs out of total risks. Concept phase has $5 \%$ MR and $15 \%$ NRs. Architecture Phase has $20 \%$ NRs; development phase has $5 \% \mathrm{CR}$, MR and NR each. Testing has $10 \% \mathrm{CRs}, 5 \% \mathrm{MR}$ and LR each. Validation and launch have $10 \% \mathrm{CRs}, 5 \% \mathrm{MR}, \mathrm{LR}$ and NR each (Fig. 10). The concept and development phases have more MRs and NRs as compared to other phases. Results of prioritizing MPD process risks using fuzzy FMEA are found to be more logical as compared to traditional FMEA. It filtered the critical risks from 40 to $25 \%$, which helps to deal with CRs, efficiently and effectively.

The study provides a detailed methodology for the developers, managers and researchers to explore MPD process risks and perform risk management using traditional

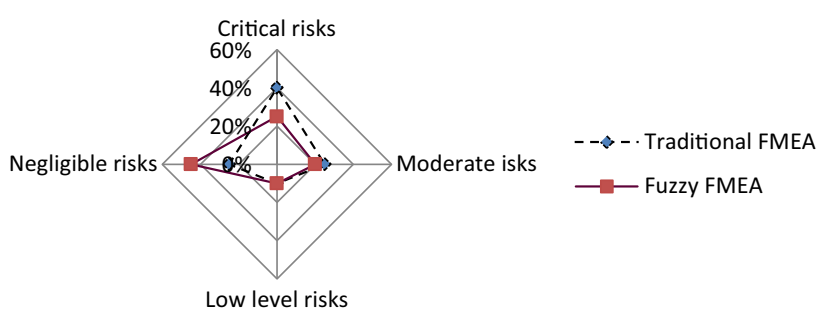

Fig. 9 Comparison between results of traditional FMEA and fuzzy FMEA based on criticality of risks 


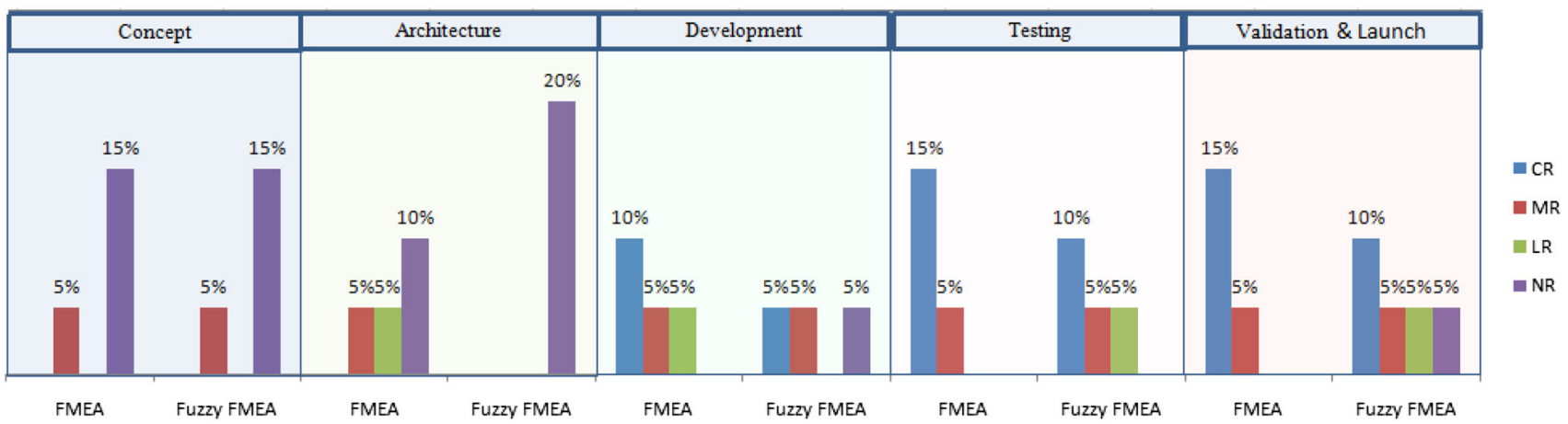

Fig. 10 Distribution of CRs, MRs, LRs and NRs along phases

FMEA and fuzzy FMEA approach. The risks identified though specific in nature provide a guideline for development processes of other medical products and devices. Also the use of FMEA is discussed in detail. The mitigation model will serve as a generic model for risk mitigation.

\section{Conclusion and future scope}

This paper presented a case of managing risks during MPD process. It can be concluded from this case study that MPD process has number of risks, whose management and mitigation are extremely necessary to reduce failure events due to process. During initial phases of MPD, the risks are less severe; but as the process progresses the severity of risks goes on increasing. The MPD process should be critically designed and simulated to minimize the number of risk events and their severity. Considering opinions of the experts on results, fuzzy FMEA approach gives more precise, appropriate and logical results as compared to the traditional FMEA.

The case study research has many advantages and limitations as well. The risks identified are specific for the case under consideration. The RPNs calculated, risk prioritization and categorization are also specific, but can be customized and effectively applied for other cases. The conclusions drawn are limited for the particular case; hence more number of such studies needs to be carried in future. Other techniques for risk analysis should be used and compared with the results reported here. A detailed survey of the medical product development companies will be useful in drawing statistics-based conclusions.

Acknowledgments This research work is funded by All India Council for Technical Education (AICTE) vide Ref No. 20/AICTE/ RIFD/RPS (POLICY-1) 61/2013-14. The authors express sincere thanks to all concerned authorities for the same. The authors are grateful to the management of the company for providing necessary support during field visits for the case study. The authors also thank the esteemed reviewers for their valuable suggestions in improving the quality of this paper.

Conflict of interest The authors have no conflict of interest.

Open Access This article is distributed under the terms of the Creative Commons Attribution 4.0 International License (http://creativecommons.org/licenses/by/4.0/), which permits unrestricted use, distribution, and reproduction in any medium, provided you give appropriate credit to the original author(s) and the source, provide a link to the Creative Commons license, and indicate if changes were made.

\section{References}

Braceras I, Ipinazar E, De Maeztu MA, Alava JI (2008) Risk analysis and implants. Med Eng Phy 30(9):1201-1204

Browning TR, Deyst JJ, Eppinger SD (2002) Adding value in product development by creating information and reducing risk. IEEE Trans Eng Manag 49(4):443-458

Cagliano AC, Grimaldi S, Rafele C (2011) A systemic methodology for risk management in healthcare sector. Safety Sci 49(5):695-708

Chalupnik et al (2009) International Conference on Engineering Design, ICED'09, 24-27 August, Stanford University, Stanford, CA, USA, pp 1-12

Chan SL, Ip WH, Zhang WJ (2012) Integrating failure analysis and risk analysis with quality assurance in the design phase of medical device development. Int J Prod Res 50(8):2190-2203

Cheng S, Das D, Pecht M (2011) Using failure modes, mechanisms, and effects analysis in medical device adverse event investigations. In: ICBO: international conference on biomedical ontology Buffalo, NY, USA

Choi HG, Ahn J (2010) Risk analysis models and risk degree determination in new product development: a case study. J Eng Tech Manag 27(1-2):110-124

Cooper LP (2003) A research agenda to reduce risk in new product development through knowledge management: a practitioner perspective. J Eng Tech Manag 20(1-2):117-140

I.S. EN ISO 14971 (2012) Medical devices. Application of risk management to medical devices (Standard for the application of risk management to medical devices)

Islam A, Tedford D (2012) Risk determinants of small and mediumsized manufacturing enterprises (SMEs) — an exploratory study in New Zealand. J Ind Eng Int 8(12):1-13 
Kayis B, Arndt G, Zhou M, Savci S, Khoo YB, Rispler A (2006) Risk quantification for new product design and development in a concurrent engineering environment. Ann CIRP 55(1):147-150

Kayis B, Arndt G, Zhou M, Amornsawadwatana S (2007) A risk mitigation methodology for new product and process design in concurrent engineering projects. Ann CIRP 56(1):167-170

Kumru M, Kumru PY (2013) Fuzzy FMEA application to improve purchasing process in a public hospital. App Soft comp 13(1):721-733

Li S, Zeng W (2014) Risk analysis of the supplier selection problem using failure modes and effects analysis (FMEA). J Intell Manuf. doi:10.1007/s10845-014-0953-0

Lin QL, Liu L, Liu HC, Wang DJ (2013) Integrating hierarchical balanced scorecard with fuzzy linguistic for evaluating operating room performance in hospitals. Exp Sys App 40(6):1917-1924

Lin QL, Wang DJ, Lin WG, Liu HC (2014) Human reliability assessment for medical devices based on failure mode and effect analysis and fuzzy linguistic theory. Safety Sci 62:248-256

Lindholm C, Host M (2009) Risk identification by physicians and developers-differences investigated in a controlled experiment. In: SEHC'09, Vancouver, Canada

Liu H, Liu L, Liu N (2013) Risk evaluation approaches in failure mode and effect analysis: a literature review. Exp Sys App 40(2):828-838

Liu HC, Chen YZ, You JX, Li H (2014) Risk evaluation in failure mode and effects analysis using fuzzy diagraph and matrix approach. J Intell Manuf. doi:10.1007/s10845-014-0915-6

Mandal S, Maiti J (2014) Risk analysis using FMEA: fuzzy similarity value and possibility theory based approach. Expert Syst Appl 41(7):3527-3537

Mariajayaprakash A, Senthilvelan T, Vivekananthan KP (2013) Optimisation of shock absorber process parameters using failure mode and effect analysis and genetic algorithm. J Ind Eng Int $9(18): 1-10$

Marmier F, Gourc D, Laarz F (2013) A risk oriented model to assess strategic decisions in new product development projects. Dec Supp Sys 56:74-82

Meherjerdi Y, Dehghenbaghi M (2013) A dynamic risk analysis on new product development process. Int J Ind Eng Prod Res 24(1):17-35

Mikkelsen H (1990) Risk management in product development projects. Risk Manag 8(4):217-221

Mu J, Peng G, MacLachlan DL (2009) Effect of risk management strategy on NPD performance. Technovation 29(3):170-180
North American Industry Classification System (NAICS) guidelines document (2015) Medical Devices Industry Assessment, pp 1-12. http://ita.doc.gov/td/health/medical\%20device\% 20industry\%20assessment\%20final\%20ii\%203-24-10.pdf

Pietzsch JB, Shluzas LA, Paté-Cornell ME, Yock PG, Linehan JH (2009) Stage-gate process for the development of medical devices. J Med Devices 3(2):021004-021004-15

Saari HL (2004) Risk management in drug development project. Helsinki University of Technology Laboratory of Industrial Management Report 2004/1, pp 1-160. http://tuta.aalto.fi/en/ midcom-serveattachmentguid-1e468c4f000159668c411e4a6e 1 d56a8c2c0eb70eb7/report_saari_012004.pdf

Schmland C (2005) Value-added medical-device risk management. IEEE Trans Device Mate Rel 5(3):488-493

Smith PG (1999) Managing risks as product development schedules shrink. Res Tech Manag Sept-Oct 1999:25-32

Song W, Ming X, Xu Z (2013) Risk evaluation of customer integration in new product development under uncertainty. Comp Ind Eng 65(3):402-412

Tang D, Yang JB, Chin KS, Wong ZSY, Liu X (2011) A methodology to generate a belief rule base for customer perception risk analysis in new product development. Exp Sys App 38(5):5373-5383

Tay KM, Lim CP (2008) On the use of fuzzy inference techniques in assessment models: part II: industrial applications. Fuzzy Optim Decis Mak 7(3):283-302

Thunnissen DP (2003) Uncertainty classification for the design and development of complex systems. In: 3rd annual predictive methods conference, Newport Beach, California, pp 1-16

Understanding Barriers to Medical Device Quality (2011) US FDA report

Unger DW, Eppinger SD (2009) Comparing product development processes and managing risk. Int J Prod Dev 8(4):382-402

Unger D, Eppinger S (2011) Improving product development process design: a method for managing information flows, risks, and iterations. J Eng Des 22(10):689-699

Vencheh A, Hejazi S, Eslaminasab Z (2013) A fuzzy linear programming model for risk evaluation in failure mode and effects analysis. Neural Comput Appl 22(6):1105-1113

Yin Robert K (1984) Case study research: design and methods. Sage Publications, Newbury Park

Zhang Z, Chu X (2011) Risk prioritization in failure mode and effects analysis under uncertainty. Exp Sys App 38(1):206-214 